\title{
Gq-Induced Apoptosis is Mediated by AKT Inhibition That Leads to PKC-Induced JNK Activation
}

\author{
Guy Nadela Zhong Yao ${ }^{a}$ Ido Ben-Amia Zvi Naor $^{\mathrm{a}}$ Rony Seger \\ aDepartment of Biological Regulation, Weizmann Institute of Science, Rehovot, ${ }^{\text {b Department of }}$ \\ Obstetrics and Gynecology, Assaf Harofeh Medical Center, Sackler School of Medicine, Rishon LeZion, \\ 'Department Biochemistry and Molecular Biology, George S. Wise Faculty of Life Sciences, Tel-Aviv \\ University, Ramat Aviv, Israel
}

\author{
Key Words \\ $\mathrm{Gq} \cdot$ Apoptosis $\cdot$ AKT $\cdot$ PKC $\cdot$ JNK
}

\begin{abstract}
Background/Aims: $\mathrm{Gq}$ protein-coupled receptors (GqPCRs) regulate various cellular processes including mainly proliferation and differentiation. In a previous study, we found that in prostate cancer cells, the GqPCR of GnRH induces apoptosis by reducing the PKCdependent AKT activity and elevating JNK phosphorylation. Since it was thought that GqPCR induces mainly activation of AKT, we undertook to examine how general is this phenomenon and understand its signaling. Methods: We used various cells to follow the phosphorylation of signaling components using western blotting. Results: In a screen of 21 cell lines, we found that PKC activation results in the reduction of AKT activity, which correlates nicely to JNK activation and in some cases to apoptosis. To further understand the signaling pathways involved in this stimulation, we studied in detail the SVOG-4O and $\alpha$ T3-1 cells. We found that PGF2 $\alpha$ and GnRH agonist ( $\mathrm{GnRH}-\mathrm{a}$ ) indeed induce significant Gq- and PKC- dependent apoptosis in these cells. This is mediated by two signaling branches downstream of PKC, which converge at the level of MLK3 upstream of JNK. One branch consists on C-Src activation of the JNK cascade and the second involves reduction of AKT activity that alleviates its inhibitory effect on MLK3, to allow the flow of the c-Src signal to JNK. At the MAPKK level, we found that the signal is transmitted by MKK7 and not MKK4. Conclusion: Our results present a general mechanism that mediates a GqPCR-induced, death receptors-independent, apoptosis in physiological, as well as cancer-related systems.
\end{abstract}




\section{Cellular Physiology Cell Physiol Biochem 2018;50:121-135

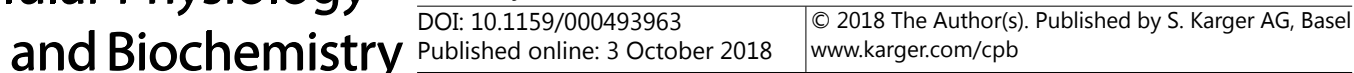 \\ Nadel et al.: Gq-Induced AKT Inactivation in Apoptotic Signaling}

\section{Introduction}

G protein-coupled receptors (GPCRs), also termed serpentine receptors, are the largest group of membranal proteins that mediate cellular responses to a wide variety of extracellular agents [1-4]. The intracellular transmission of GPCR signals is mediated mainly by heterotrimeric $\mathrm{G}$ proteins, which are divided into four groups: Gs, Gi, Gq and G12, according to the downstream effectors of their subunit. The $\beta \gamma$ subunits of the $G$ proteins $[5$, 6], as well as G-protein independent signaling $[7,8]$ also contribute to the wide functional array of the various receptors, which include proliferation, differentiation, vision, olfaction stress response and more. Among all G proteins, the four members of the Gq family (Gq, G11, G14 and G15/16) function primarily via activation of phospholipase C- $\beta[9,10]$. This effector then produces the second messengers: inositol trisphospate and diacylglycerol, which further elevate intracellular calcium levels as well as protein kinase C (PKC) activity to induce many intracellular signaling and a plethora of GqPCR-induced effects.

As the other members of the GPCR family, the GqPCRs induce a wide array of cellular processes. Studies using Gq knockout in mice demonstrated a role of this protein in platelet activation, as well as in the development and functioning of the central nervous system and the heart $[11,12]$. Other GqPCR-regulated effects have been identified by other methods including regulation of proliferation [13], the reproductive system [14], brain functioning [9], and more [15]. Aside of these GqPCR-induced effects, these central receptors were also implicated in growth arrest or apoptosis in few pathological systems [15-17]. For instance, cardiac hypertrophy seems to be mediated by auto/paracrine mediators acting through GqPCRs [18, 19], and gonadotropin-releasing hormone (GnRH [20]) was shown to induce apoptosis of prostate cancer cells through its GqPCR [21]. Surprisingly, overexpression of constitutively active Gq induces apoptosis of COS7, CHO [22], and HeLa [23] cells as well.

Since GqPCR are distinct from the classical death receptors and cannot recruit caspases or known apoptotic adaptors, the molecular mechanism by which these receptors induce apoptosis attracted considerable attention. Interestingly, the mechanisms identified seem to vary between the different systems. Thus, while the apoptotic effects in COS7 and CHO cells are mediated by PKC [22], AT2-induced myocyte apoptosis was found to be dependent on the elevation of intracellular $\mathrm{Ca}^{2+}$ [18]. In addition, it was proposed that GqPCR-mediated apoptosis in myocyte might be dependent on permeability transition, pore formation, and activation of the mitochondrial death pathway due to dysregulation of intracellular $\mathrm{Ca}^{2+}$ levels [24]. These effects may also be mediated by additional intracellular signaling mechanisms including JNK, p38, RhoK [16], and novel autophosphorylation of ERK that modulates its activity to induce hypertrophic gene expression [25]. However, the full signaling in all these systems needs further clarification.

Another signaling pathway that seems to play a role in GqPCRs action is the one involving the lipid kinase phosphatidylinositol 3 kinase (PI3K) and the protein Ser/Thr kinase AKT [26]. The mechanism of activation of this pathway is normally initiated by stimulus-dependent recruitment of PI3K to the plasma membrane, which is mediated either by binding to phospho-Tyr residues in membranal proteins, or to a GTP-bound Ras [27]. This recruitment allows PI3K to phosphorylate phosphoinosited, and further recruit to this location $\mathrm{PH}$ domain-containing proteins. One such protein is AKT, which upon shifting, is phosphorylated on Thr308 by PDK1 and on Ser473 by mTORC2, to induce its full activation. Activated AKT then phosphorylates a large number of substrates to execute many cellular processes, which include mainly cellular metabolism and survival [28]. Interestingly, although this pathway seems to be activated by most GqPCRs [15], some reports showed that activation of certain Gq proteins actually reduces AKT activation. These include GnRH receptor that counteracts IGF-1 in $\alpha$ T3-1 cells [29], m1 muscarinic receptor that counteracted insulin in HeLa cells [30], and constitutively active Gq that counteracted EGF in HEK293 cells [31]. However, the mechanism of GqPCRs effect on growth factor-induced AKT activation is not fully elucidated. 


\section{Cellular Physiology Cell Physiol Biochem 2018;50:121-135

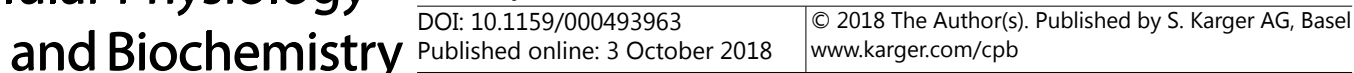 \\ Nadel et al.: Gq-Induced AKT Inactivation in Apoptotic Signaling}

In a previous study we found that GnRH not only inhibits growth-factor stimulated AKT activation, but can reduce the high basal phosphorylation of this kinase in prostate cancer cells as well [21]. This reduced phosphorylation and activity alleviates the inhibitory effects of AKT on the pro-apoptotic JNK cascade and therefore induced cell death. Since it was previously thought that most stimuli elevate AKT activity and therefore lead to survival, it was not clear how general is the inhibitory effect observed in the prostate cancer cells. In order to investigate these points, we first conducted a screen on the effect of TPA, which mimics the GqPCR activation, on 21 distinct cell lines. To our surprise, AKT phosphorylation was reduced in 11 cell lines, and this was correlated with elevated JNK phosphorylation and to TPA-induced apoptosis. To elucidate the full signaling machinery that links these effects, we used the two cell lines in which TPA induced the strongest apoptosis SVOG-40 and $\alpha$ T3-1. We found that stimulation of these cells with Prostaglandin F2 (PGF2 $\alpha$ ) or GnRH, respectively, results in a Gq-dependent apoptosis. The signaling mechanisms involved in this process can be divided into two pathways downstream of PKC. One acts via c-Src to activate MLK3 and the rest of the JNK cascade, while the other acts via inactivation of AKT to alleviate its inhibitory MLK3 phosphorylation. Thus, GqPCRs can serve as apoptotic receptors, acting via a common physiological and pathological PKC-dependent activation of c-Src and reduction of PI3K/AKT activity to induce JNK-dependent apoptosis.

\section{Materials and Methods}

\section{Reagents antibodies and plasmids}

[D-Ala] ${ }^{6} \mathrm{GnRH}$ (GnRH-a), protein A-Sepharose and 12-0-tetradecanoyl-phorbol-13-acetate (TPA) were obtained from Sigma (St. Louis, MO). GF109203X, U0126, SB203580, PP2, SP600125, okadaic acid and wortmannin were from Calbiochem (San Diego, CA, USA). 8-iso PGF2 $\alpha$ was from Cayman Chemical (Ann Arbor, MI). Anti-pERK and pJNK antibodies (Abs), and anti ERK, JNK, and AKT Abs, were from Sigma, Israel. Anti pSer473-AKT, Rabbit polyclonal anti pThr308-AKT, cleaved caspase-3, c-Src, pTyr416-Src, pSer271/ Thr275-MKK7, pSer80-MKK4, pThr261-MKK4, pSer83-ASK1, pThr277/Ser281-MLK3, pSer/Thr AKTsubstrate, MLK3, and ASK1 Abs were from Cell Signaling Technology (Danvers, MA, USA). Anti-tubulin, MKK4 and MKK7 Abs were from Santa Cruz Biotechnology (Santa Cruz, CA, USA). HA-Gq and HA-Q209L-Gq in pCDNA3 were a gift from Dr. Ulrike Mende from Brown University Providence, RI, USA.

\section{Buffers}

RIPA buffer: $137 \mathrm{mM} \mathrm{NaCl}, 20 \mathrm{mM}$ Tris-HCl, pH 7.4,10\% glycerol, 1\% Triton X-100, 0.5\% deoxycholate, $0.1 \%$ SDS, $2 \mathrm{mM}$ EDTA, $1 \mathrm{mM}$ phenylmethylsulphonyl fluoride, $1 \mathrm{mM} \mathrm{Na}_{3} \mathrm{VO}_{4}$, and $20 \mu \mathrm{M}$ leupeptin. Buffer A: $50 \mathrm{mM}$ $\beta$-glycerophosphate, pH 7.3, $1.5 \mathrm{mM}$ EGTA, $1 \mathrm{mM}$ EDTA, $1 \mathrm{mM}$ DTT, and $0.1 \mathrm{mM} \mathrm{Na}_{3} \mathrm{VO}_{4}$. Buffer H: 50 $\mathrm{mM} \beta$-glycerophosphate, pH 7.3, $1.5 \mathrm{mM}$ EGTA, $1 \mathrm{mM}$ EDTA, $1 \mathrm{mM}$ DTT, $0.1 \mathrm{mM} \mathrm{Na}_{3} \mathrm{VO}_{4}, 1 \mathrm{mM}$ benzamidine, $10 \mu \mathrm{g} / \mathrm{ml}$ aprotinin, $10 \mu \mathrm{g} / \mathrm{ml}$ leupeptin, and $2 \mu \mathrm{g} / \mathrm{ml}$ pepstatin-A.

\section{Cell culture and activations}

SVOG-40 cells were from N. Auersperg (University of British Columbia, Vancuver, Canada). Cells were cultured in M-199/MCDB 105 containing 10\% FCS, (Gibco Carlsbad, CA, USA) and gentamycin (50 $\mu \mathrm{g} / \mathrm{ml}$ ). Serum-starvation was with $0.1 \%$ FCS in the same medium for $16 \mathrm{hr}$. $\alpha \mathrm{T} 3-1$ cells, were cultured in DMEM supplemented with 10\% Dextran-coated charcoal-treated fetal calf serum (DCC-FCS) (Biological Industries, Beit-Haemek, Israel), $2 \mathrm{mM} \mathrm{L-glutamine,} \mathrm{penicillin} \mathrm{and} \mathrm{streptomycin} \mathrm{(100U/ml).} \mathrm{Serum-starvation} \mathrm{was} \mathrm{with}$ $0.1 \%$ DCC-FCS in the same medium for $16 \mathrm{hr}$. HeLa cells were cultured in DMEM with $10 \% \mathrm{FCS}$, penicillin and streptomycin $(100 \mathrm{U} / \mathrm{ml})$. Serum-starvation was with $0.1 \%$ FCS in the same medium for $16 \mathrm{hr}$. Stimulation was performed, either after or without preincubation with inhibitors, with PGF2 $\alpha(\mu \mathrm{M}), \mathrm{GnRH}-\mathrm{a}\left(10^{-7} \mathrm{M}\right)$, TPA (250 nM), and the positive control VOOH (100 $\mu \mathrm{M} \mathrm{Na}_{3} \mathrm{VO}_{4}$ and $\left.200 \mu \mathrm{M} \mathrm{H}_{2} \mathrm{O}_{2}\right)$. 


\section{Cellular Physiology Cell Physiol Biochem 2018;50:121-135

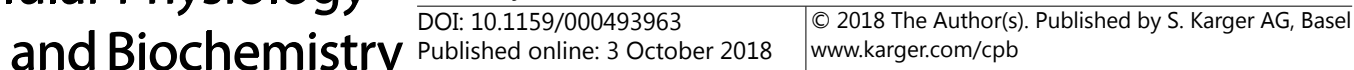 \\ Nadel et al.: Gq-Induced AKT Inactivation in Apoptotic Signaling}

TUNEL assay

To analyze apoptosis, subconfluent SVOG-40, $\alpha$ T3-1 or HeLa cells were plated on glass coverslips in 12 well plates under the standard culture conditions as described above. Twenty-four hr after the initial seeding, cells were serum-starved and then treated. At different times after treatment the cells were fixed with paraformaldehyde solution ( $4 \%$ in PBS ( $\mathrm{pH} 7.4)$ for $1 \mathrm{hr}$ at $\left.15-25^{\circ} \mathrm{C}\right)$, washed with PBS and then incubated with $0.1 \%$ Triton X-100 in $0.1 \%$ sodium citrate $\left(2 \mathrm{~min}, 4^{\circ} \mathrm{C}\right)$, washed again with PBS, and incubated with terminal deoxynucleotidyltransferase-mediated nick end labeling (TUNEL) mixture containing fluorescein-dUTP and terminal deoxy-nucleotidyl transferase (Roche Molecular Biochemicals) for $30 \mathrm{~min}$ at $37^{\circ} \mathrm{C}$. Preparations were analyzed by fluorescence microscopy. The incidence of apoptosis was determined by counting 200 cells.

\section{Cell harvesting, SDS-PAGE and Western blot}

Cells were grown to subconfluency, serum-starved, and stimulated for various times. After treatment, the cells were rinsed twice with ice-cold PBS and either rinsed with ice-cold Buffer A and scraped into Buffer $\mathrm{H}$ and disrupted by sonication or scraped into RIPA buffer. The extracts were centrifuged $(15,000 \times \mathrm{xg} 15 \mathrm{~min}$, $4^{\circ} \mathrm{C}$ ) and the supernatants were boiled ( $5 \mathrm{~min}$ ) in sample buffer. The samples were then subjected to $10 \%$ SDS-PAGE and Western blotting with the appropriate Abs that were detected using alkaline phosphatase or ECL according to the manufacturer's instructions.

\section{Immunoprecipitation (IP) and Co-Immunoprecipitation (CoIP)}

Cells were treated and extracted as above. The extracts were incubated $\left(2 \mathrm{~h}, 4^{\circ} \mathrm{C}\right)$ with $\mathrm{A} / \mathrm{G}$-conjugated $\mathrm{Ab}$, and for IP the beads were washed twice with RIPA, once with $0.5 \mathrm{M} \mathrm{LiCl}$ in $0.1 \mathrm{M}$ Tris pH 8.0, and once with PBS. For Co-IP the beads were washed three times with buffer A. Both IP and CoIP reactions were boiled in sample buffer and then subjected proteins were then subjected to 10\% SDS-PAGE and Western blotting.

\section{SiRNA and cell transfection}

SiRNAs were from Dharmacon (Lafayette, CO, USA). Transfection of the SiRNA was made by using DharmaFECT according to the manufacturer's instructions. Transfection of plasmids into cells was done using PEI [32].

\section{Results}

Different effects of TPA on AKT, JNK and apoptosis in various cell line

In a previous study we found that GnRH reduces the high basal phosphorylation of AKT in starved prostate cancer cells and this led to JNK activation and apoptosis [21]. Since it is usually assumed that stimuli should activate AKT rather than inactivating it, we undertook first to study how general is this phenomenon. For this purpose, we studied the effect of TPA on AKT, JNK and caspase 3 in 21 distinct cell lines. To our surprise, we found that AKT phosphorylation was significantly reduced in 11 of the cell lines (Fig. 1), while in other cells the phosphorylation of AKT was not changed ( 6 cell lines) or elevated (4 cell lines). This reduced AKT activity correlated with elevated JNK phosphorylation that was detected in 10 out the 11 cells in which AKT phosphorylation was reduced, but not in any of the other cell lines. Importantly, 5 of the cell lines exhibited TPA-induced caspase 3 cleavage that is a marker of apoptosis. Four out of them were cells in which AKT phosphorylation was reduced and JNK phosphorylation was elevated. These results, together with our previous finding with DU145 cells (16), suggest a common linkage of PKC, AKT and JNK to apoptosis in many cells. Thus, unlike previous thoughts, the PKC-induced AKT inactivation that leads to JNK phosphorylation and apoptosis seems to be a widespread signaling process that worth further study. 


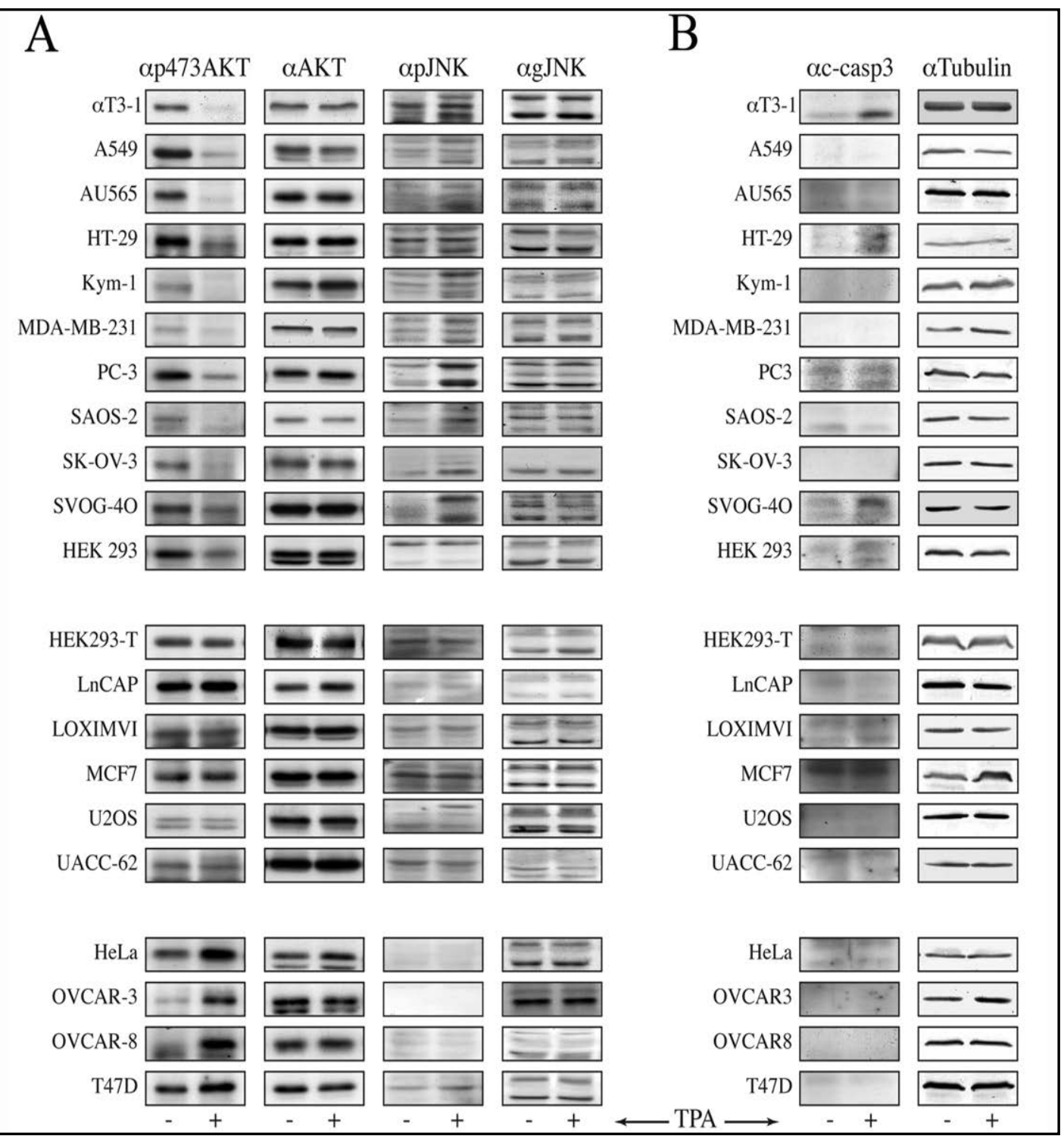

Fig. 1. Effect of TPA on AKT, JNK and caspase 3 in different cell lines. Cells were treated with TPA (100 $\mathrm{nM}$ ) for $30 \mathrm{~min}$ (A) or $48 \mathrm{hr}$ (B). The cell lysates were subjected to Western blot analysis. The activation of Akt and JNK was determined by anti-phospho antibodies (A) and apoptosis was evaluated by anti-cleaved caspase 3 antibody (B).

\section{PGF2 $\alpha$ and GnRH- $a$ induce apoptosis in SVOG-4O and $\alpha$ T3-1 Cells}

To further characterize the signaling pathway and elucidate its importance, we chose to study the two cell lines in which TPA induced the strongest apoptosis, namely the SVOG40 and $\alpha \mathrm{T} 3-1$ cells. Interestingly, these lines represent cells that may undergo physiological apoptosis, upon GqPCR/PKC stimulation. Thus, SVOG-40 are leutinized granulosa cells that were reported to undergo luteolytic apoptosis following prostaglandin F2 (PGF2 $\alpha$ )-exposure $[33,34]$. The other was based on the pituitary-derived $\alpha \mathrm{T} 3-1$ cells that undergo apoptosis in response to GnRH. Although the exact function of apoptosis in the pituitary is not clear, it is likely to play a role in gonadotrope development, similarly to the effect of GnRH on the development of hypothalamic GnRH-neurons [35]. Therefore, the study of these systems may contribute not only to understanding of PKC-related apoptosis, but also to physiological importance of GqPCR/PKC-induced apoptotic signaling, which was previously thought to occur only under pathological settings [15-17].

\section{KARGER}


Fig. 2. $P G F 2 \alpha / G n R H-a$ stimulation induces apoptosis in SVOG-40 and $\alpha$ T3- 1 cells. A. Serumstarved SVOG-40 (left) and $\alpha \mathrm{T} 3-1$ cells (right) were either treated with PGF2 $\alpha(1 \mu \mathrm{M})$ and GnRH-a $\left(10^{-7} \mathrm{M}\right)$ for $24 \mathrm{hr}$ or left untreated. PGF2 $\alpha$ / GnRH-a-induced cell death was detected by TUNEL and number of nuclei by DAPI. B. Serumstarved SVOG-40 (left) and $\alpha \mathrm{T} 3-1$ cells (right) were either treated with PGF2 $\alpha$ (left) or GnRH-a (right) for different times, different concentrations, or left untreated. PGF $2 \alpha$ / GnRH-a-induced cell death was detected by TUNEL. C. Serum-starved SVOG-40 (left) and $\alpha$ T3-1

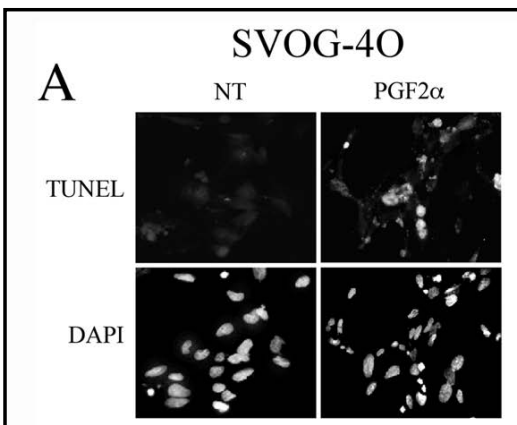

$\mathrm{B}$

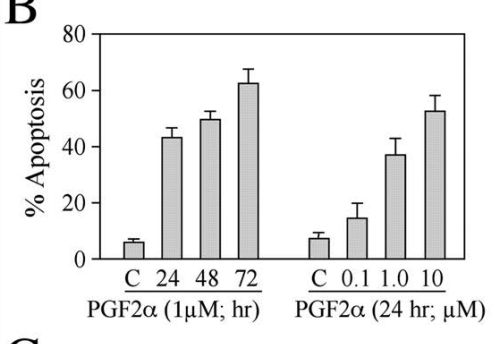

C

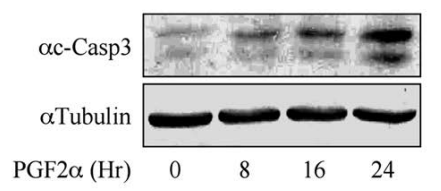

aT3-1
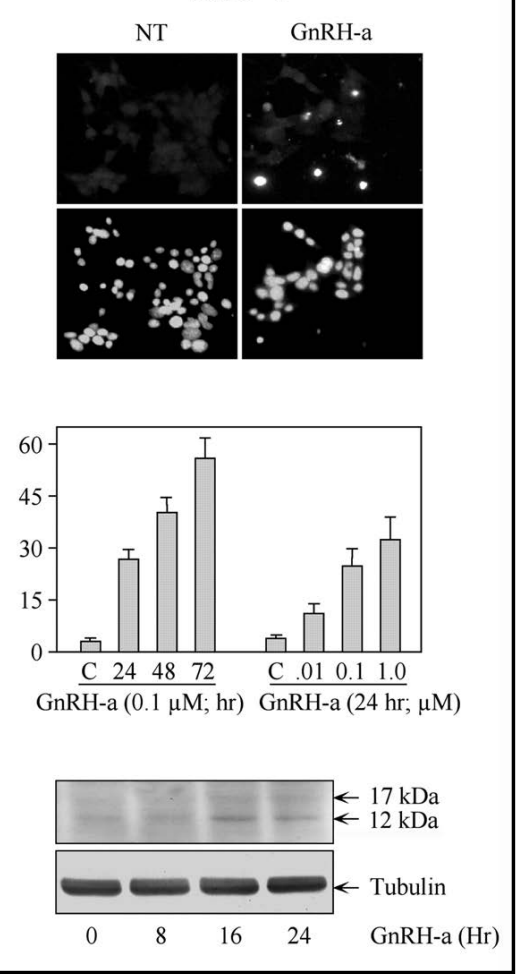
cells (right) were either treated with PGF2 $\alpha(1 \mu \mathrm{M})$ or GnRH-a $\left(10^{-7} \mathrm{M}\right)$ for different times or left untreated. Cleaved caspase-3 was detected by anti-cleaved caspase-3 $\mathrm{Ab}$.

For this purpose, we stimulated the two cell lines with their physiological stimuli, which due to the interaction of their receptors with Gq, are likely to induce PKC activation in a more physiological way than the TPA used in the screen. Thus, we first treated the SVOG-40 cells with PGF $2 \alpha$ and found that this treatment resulted in a significant time- and dose-dependent apoptosis, as judged from TUNEL (up to $63 \pm 5 \%$ after $72 \mathrm{hr}$ with $1 \mu \mathrm{M}$ PGF $2 \alpha$ ) and caspase 3 cleavage (Fig. 2). Similar to the PGF2 $\alpha$ effect, GnRH-a that was added to the $\alpha \mathrm{T} 3-1$ cells induced significant apoptosis as well (Fig. 2). Since this apoptosis was also induced by TPA (Fig. 1), and was affected by PKC inhibitors (data not shown), it is likely that the effect was indeed GqPCR/PKC-dependent.

\section{Gq protein induces apoptosis in SVOG-4O and $\alpha$ T3-1 but not HeLa cells}

We then undertook to further verify that PGF $2 \alpha$ and GnRH-a induce their function via Gq, which may then induces further signaling through PLC $\beta$, and PKC [9]. For this purpose, we overexpressed WT-Gq as well as its constitutively active form Q209L-Gq in SVOG-40, $\alpha$ T3-1 and HeLa cells. TUNEL, as well as caspase 3 cleavage assays revealed that both Gq constructs induced a significant level of apoptosis (Fig. 3). As with PGF2 $\alpha$ this proapoptotic stimulation was accompanied by a reduced AKT and an elevated JNK phosphorylation. Similar results were obtained with $\alpha \mathrm{T} 3-1$ cells, although the effects of the constitutively active isoform were stronger than that of WT-Gq. Interestingly, the overexpression of these constructs in HeLa cells had no significant effect on the parameters examined. This result opposes previous findings [23], which might be probably due to the use of serum-starvation in our experiments. Thus, our data suggests that the ability of Gq to induce apoptosis is dependent on cellular contexts. Moreover, our results indicate that PGF2 $\alpha$ and GnRH-a-induced apoptosis is indeed mediated primarily by Gq. 
Fig. 3. Overexpression of $\mathrm{Gq}$ induces apoptosis in SVOG-40 and $\alpha \mathrm{T} 3-1$ cells. SVOG-40, $\alpha$ T3-1 and HeLa cells were transfected with WT-Gq, Q209L-Gq or empty plasmids. Twenty-four hr after transfection, the cells were serum-starved for $16 \mathrm{hr}$ and apoptosis was detected by TUNEL and DAPI (right panels). Alternatively, the cells were lysed, and the cell extracts were subject to Western blotting with anti p473AKT, gAKT, pJNK, gJNK, cleaved caspase- 3 and $\mathrm{Gq}$ Abs as indicated (left panels).

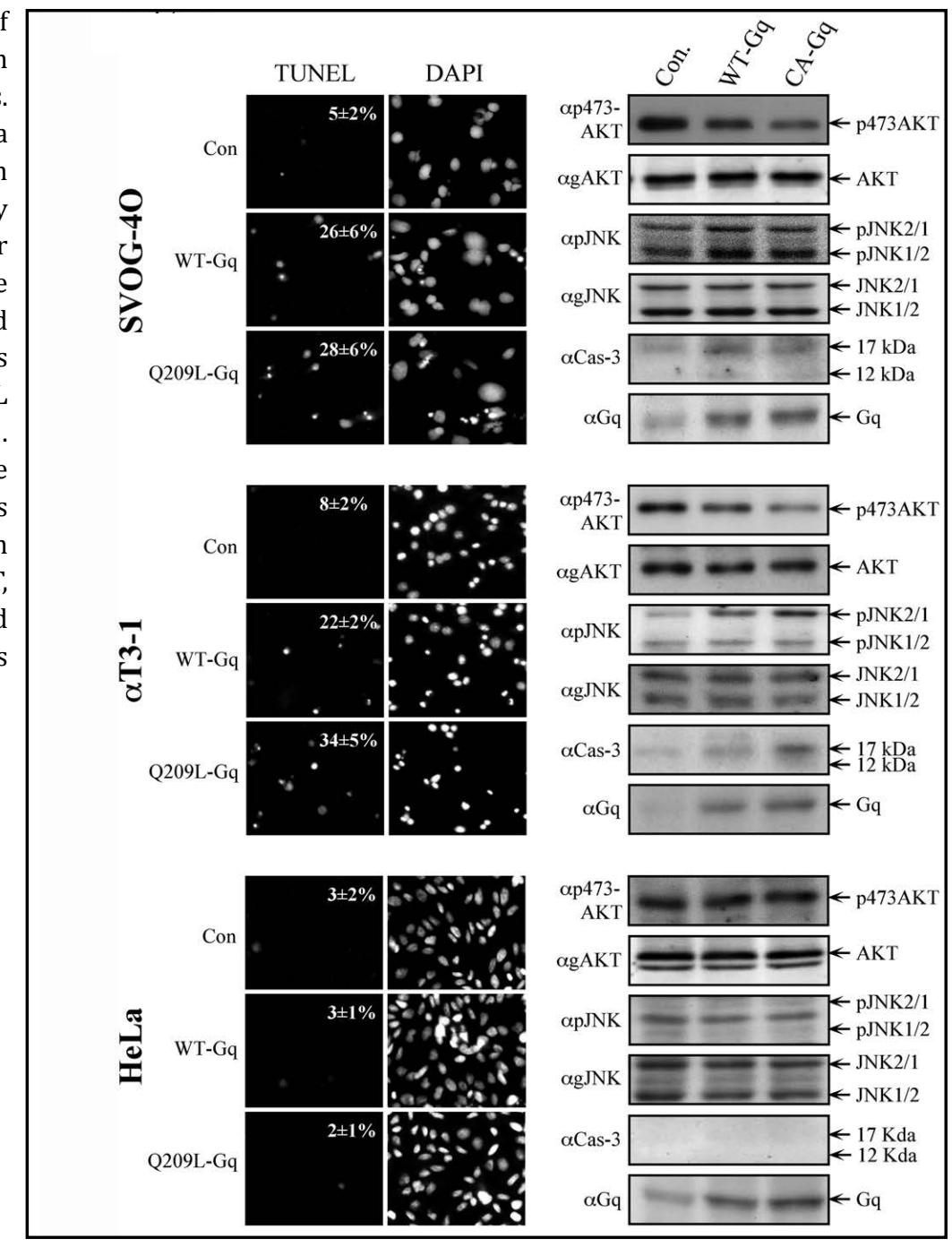

Signaling pathways affected by the proapototic PGF2a and GnRH-a

We then examined the effect of the two stimuli on AKT, JNK as well as p38 and ERK that have been demonstrated to be activated by GPCRs in many cell types [36]. As expected, the phosphorylation of three MAPKs examined was increased upon both stimulations. However, only the kinetics of JNK phosphorylation was similar in both cell lines (peaking at $30 \mathrm{~min} ; 10 \pm 2.3$-fold induction; Fig. $4 \mathrm{~A}$ ), while the pattern of p38 and more so of ERK1/2 phosphorylation was stronger in GnRH-a-stimulated $\alpha \mathrm{T} 3-1$ cells (Fig. 4, B and C). AKT phosophorylation was detected by Abs directed to both phosphorylation sites Thr308 and Thr473. In all cases, AKT demonstrated high basal phosphorylation that was significantly reduced within 5-30 min of stimulation and remained low for at least 90 min of stimulation (Fig. 4D). This result is likely to be exerted by removal of phosphate from nuclear AKT (Fig. S1A - for all supplementary material see www.karger.com/10.1159/000493963/), and as expected, the reduction in AKT phosphorylation correlated with reduction in its catalytic activity (Fig. S1B) . Inhibition or activation of PKC by its specific inhibitors GF109203X or TPA revealed that the stimulus-dependent dephosphorylation of both Ser308 and Ser473 is dependent on PKC (Fig. S2). On the other hand, c-Src that have previously been shown to act downstream of PKC in $\alpha \mathrm{T} 3-1$ cells [36, 37], was indeed activated in both cell types (Fig. S3), but its inhibition affected only the basal and not stimulated reduction in AKT phosphorylation. This indicates that Gq transmits signals to AKT via PKC, but not c-Src, although the latter is a mediator of the high basal AKT activity in these cells. 
Fig. 4. Modulation of MAPKs and AKT phosphorylations in PGF2 $\alpha / \mathrm{GnRH}$-a-induced apoptosis. A-D. Serumstarved SVOG-40 (left) and $\alpha \mathrm{T} 3-1$ (right) cells were treated with PGF2 $\alpha$ (10 $\mu \mathrm{M})$ and GnRH-a $\left(10^{-7} \mathrm{M}\right)$ for the indicated times or with $\mathrm{VOOH}(\mathrm{V})$ for 20 min as a positive control. Phosphorylation of MAPKs and AKT was determined using Western blotting with the indicated Abs. E. Serum-starved SVOG-40 (left) and $\alpha \mathrm{T} 3-1$ cells (right) were pre-treated with JNK inhibitor SP600125 (SP, $5 \mu \mathrm{M})$, MEK1/2 inhibitor U0126 (U0, $5 \mu \mathrm{M}$ ), PI3K inhibitor Wortmannin (Wo, $100 \mathrm{nM}$ ) or SB203580 (SB, $10 \mu \mathrm{M})$, and then stimulated with PGF2 $\alpha(1 \mu \mathrm{M})$ and GnRH-a $\left(10^{-7} \mathrm{M}\right)$ for $24 \mathrm{hr}$. Apoptosis was detected by TUNEL and DAPI. * - $\mathrm{P}<0.01$, \# - $\mathrm{P}<0.05$ compared to first bar in each.

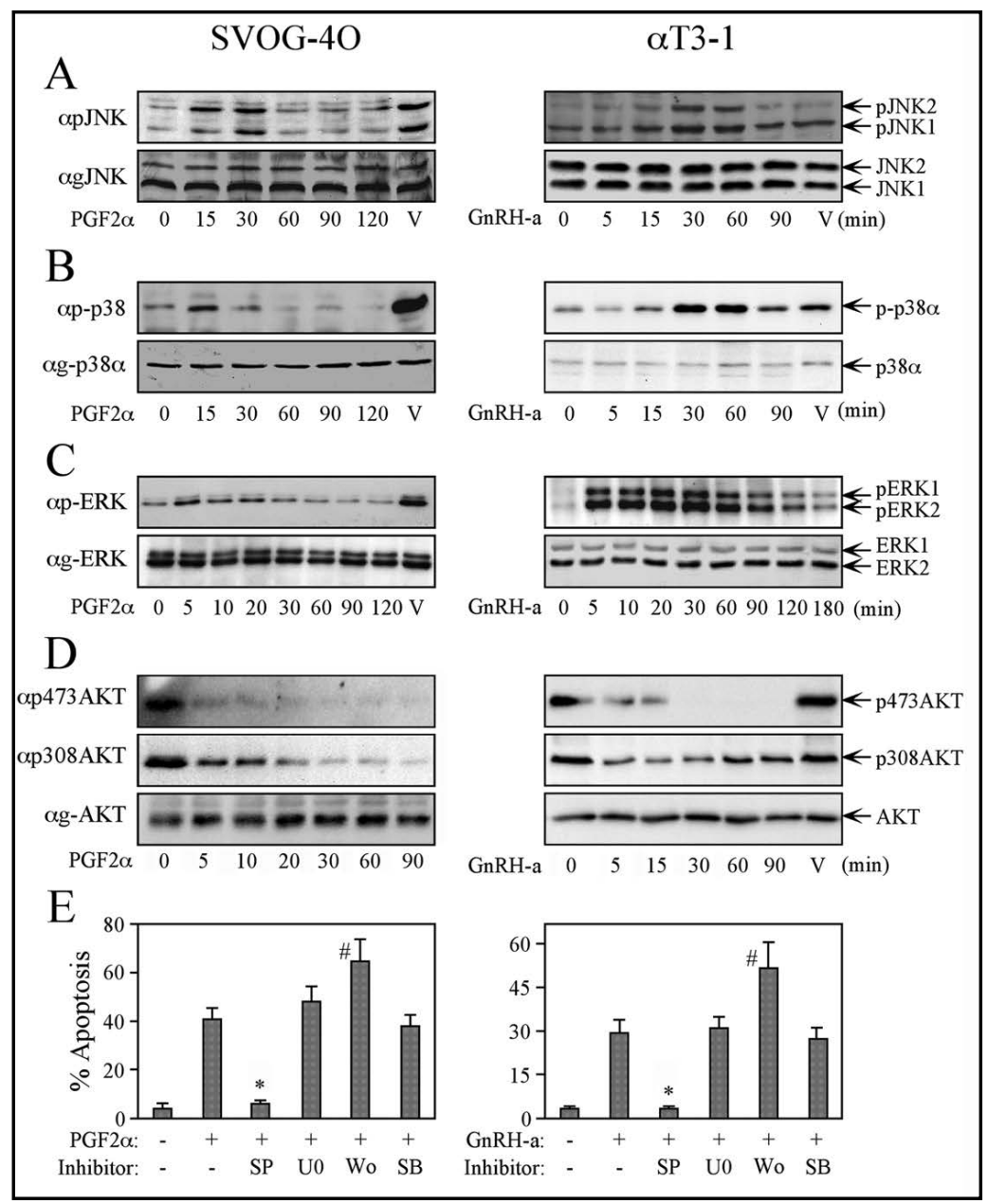

Fig. $\quad 5 . \quad \mathrm{JNK}$ phosphorylation upon GnRH-a/ PGF2 $\alpha$ stimulation is mediated by PKC, c-Src and AKT. A. Serumstarved SVOG-40 (left) and $\alpha \mathrm{T} 3-1$ cells (right) were pre-treated with the c-Src inhibitor PP2 (2 $\mu \mathrm{M}, 20 \mathrm{~min})$, the PI3K/AKT inhibitor wortmannin (Wort; $25, \mathrm{nM}, 20 \mathrm{~min}$ ) and

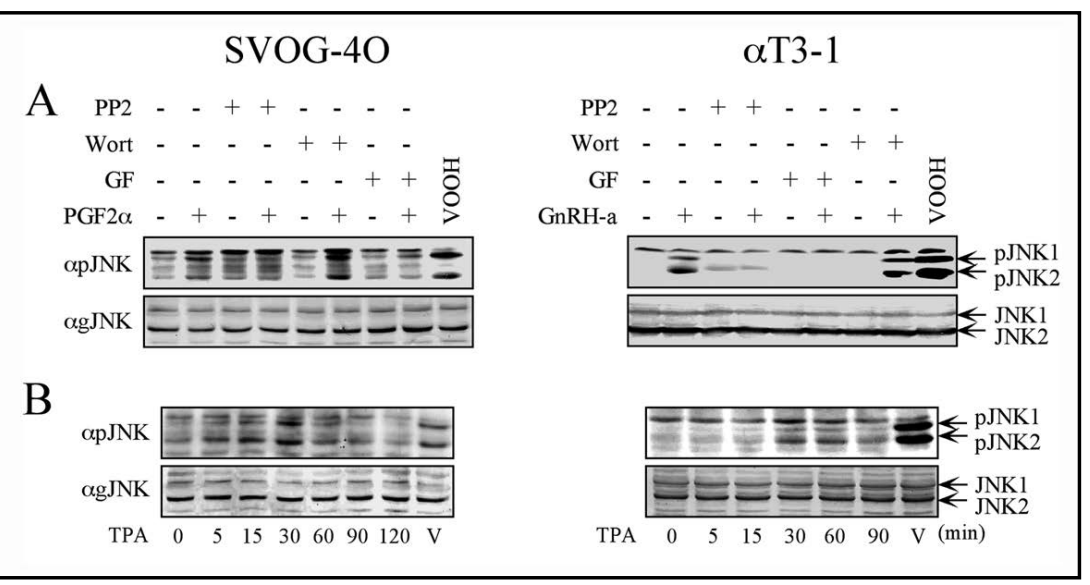
the PKC inhibitor GF109203X (GF; $3 \mu \mathrm{M}, 20 \mathrm{~min}$ ) or left untreated. Thereafter, the cells were stimulated with PGF2 $\alpha$ (10 $\mu \mathrm{M}, 30 \mathrm{~min})$ and $\mathrm{GnRH}-\mathrm{a}\left(10^{-7} \mathrm{M}, 30 \mathrm{~min}\right)$ or VOOH (18 min). Phosphorylation of JNK was determined by a Western blotting using the indicated Abs. B. Serum-starved SVOG-4O (left) and $\alpha \mathrm{T} 3-1$ (right) cells were treated with TPA (250 nM) for the indicated times or VOOH (V) for 20 min. Phosphorylation of JNK was determined by Western blotting using the indicated Abs. 
We then used selective inhibitors to identify the signaling components participating in the apoptotic effect in both systems. For this purpose, we pretreated both cell lines with specific inhibitors to JNK (SP600125), MEK (U0126), PI3K (wortmannin) and p38 (SB203580), followed by stimulation. TUNEL assay on the treated cells (Fig. 4E) revealed that in both cell lines the stimulated apoptosis was inhibited by the JNK inhibitor, activated by the PI3K inhibitor and not affected by the two other inhibitors. Thus, the apoptotic effect observed in granulosa and pituitary cells is mediated by reduced PI3K/AKT activity downstream of PKC and by elevated JNK activity.

Fig. 6. MLK3 is involved in PGF2 $\alpha /$ GnRH-a-induced AKT-mediated JNK activation. A. Serumstarved SVOG-40 (left) and $\alpha \mathrm{T} 3-1$ (right) cells were treated with PGF2 $\alpha$ $\left(\begin{array}{ll}10 & \mu \mathrm{M}\end{array}\right) \quad$ GnRH-a $\left(10^{-7} \mathrm{M}\right)$ for the indicated times, or $\mathrm{VOOH}$ as a positive control for $20 \mathrm{~min}$. (V). Phosphorylation of MLK3 on Thr277/ Ser281 was determined using the indicated Abs. B. Serum-starved SVOG-40 cells were treated with TPA $(250 \mathrm{nM})$ for the indicated times or $\mathrm{VOOH} \mathrm{(V)} \mathrm{for} 15$ $\min$ as a positive control. Activatory phosphorylation

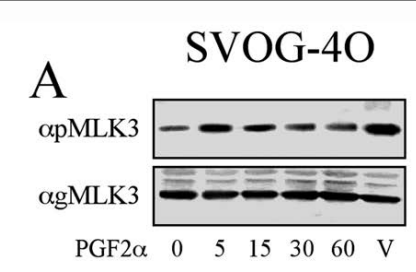

B

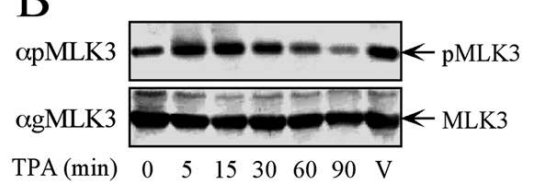

C

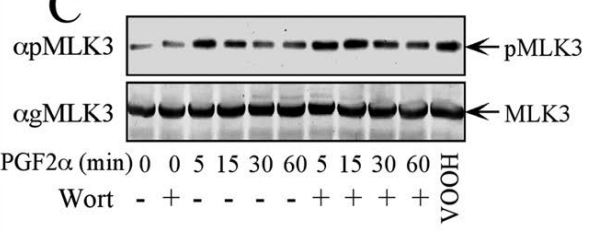

F

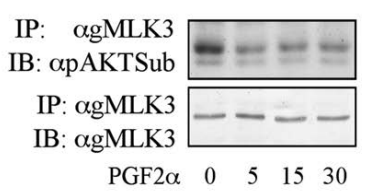

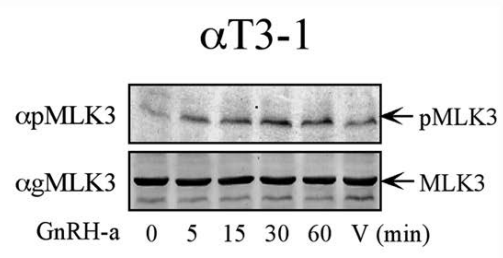

D

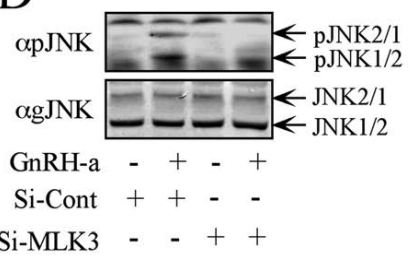

Si-MLK3 - - +

E

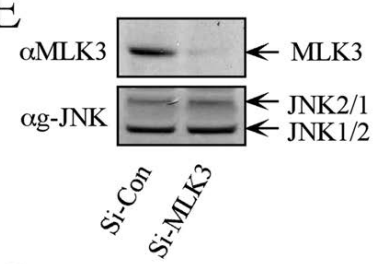

G

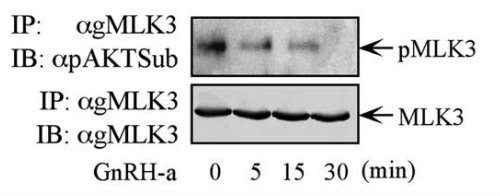

of MLK3 was

determined by Western blotting using the indicated Abs. C. Serum-starved SVOG-40 cells were either pretreated with wortmannin (Wort; $25 \mathrm{nM}, 20 \mathrm{~min},+$ ) or vehicle control (-), and then treated with PGF2 $\alpha$ $(10 \mu \mathrm{M})$ for the indicated times. In parallel the cells were treated with VOOH for $20 \mathrm{~min}$ that served as a positive control. Activatory phosphorylation of MLK3 was determined by Western blotting using the indicated Abs. D, E. $\alpha$ T3-1 cells were transfected with SiRNA of MLK3, serum-starved and stimulated with GnRH-a (10 $\left.10^{-7} \mathrm{M}, 30 \mathrm{~min}\right)$. The activatory phosphorylation of JNK (D) and the expression of MLK3 (E) were determined by Western blotting of the same membrane (bottom panels in both showing gJNK). First the membrane was blotted with pJNK Ab (D - upper panel), stripped, blotted with gJNK Ab (D, and E - bottom panels), and then stripped again and blotted with MLK3 Ab (E, upper panel). F,G, Serum-starved SVOG-4O (F) and $\alpha$ T3-1 (G) cells were treated with PGF2 $\alpha(10 \mu \mathrm{M})$ and GnRH-a $\left(10^{-7} \mathrm{M}\right)$ for the indicated times or left untreated (0). Cells were then subjected to IP with anti-MLK3 Ab, and its inhibitory phosphorylation by AKT was detected by Western blot analysis using anti-pSer/Thr-AKT substrate and MLK3 Abs. 


\section{Cellular Physiology Cell Physiol Biochem 2018;50:121-135 \begin{tabular}{ll|l} 
DOI: 10.1159/000493963 & and Biochemistry 2018 The Author(s). Published by S. Karger AG, Basel \\
www.karger.com/cpb
\end{tabular}

JNK Activation by GnRH- $a$ and PGF2 $\alpha$ is mediated by MLK3, PKC, $c$-Src and AKT

As shown above, asides of PI3K/AKT inhibition, also JNK activation plays a role in the PGF2 $\alpha / G n R H-a-i n d u c e d$ apoptosis. We therefore studied the mechanism of activation of JNK in both $\alpha \mathrm{T} 3-1$ and SVOG-4O cells. As expected, JNK activation was dependent on PKC, c-Src and inhibition of AKT as judged by pretreatment of the cells with the appropriate inhibitors (Fig. 5A) and with TPA (Fig. 5B). This indicates that PKC signal to JNK is branched into Src-dependent and AKT inactivation-dependent pathways. We then undertook to find out at what level these two pathways may converge, and focused on a MAP3K component of the JNK cascade, the MLK3, which had previously been reported to undergo inhibitory phosphorylation by AKT $[17,38]$. Therefore, we assessed the effect of PGF2 $\alpha$ and GnRH-a on the activity of MLK3 by anti-phospho Ab, which revealed an increase in MLK3 phosphorylation in both cell systems (Fig. 6A). The activation of MLK3 was clearly downstream of c-Src, PKC and PI3K/AKT, as C-Src and PKC inhibitors reduced (Fig. S4), while TPA elevated the phosphorylation (Fig. 6B). The PI3K inhibitor wortmannin enhanced and prolonged the PGF2 $\alpha$-induced activatory phosphorylation (Fig. 6C, Fig. S4). A more compelling verification for the central role of MLK3 in the Gq-JNK pathway was achieved with specific SiRNA of MLK3, which markedly reduced the expression levels of MLK3. This knockdown abolished stimulated JNK phosphorylation (Fig. 6D and E), indicating that MLK3 is the main, or even the only MAP3K, in the delineated pathway. Using anti pAKT-substrate Ab on IPed MLK3 we found that MLK3 activation is correlated with a reduced AKT phosphorylation (Fig. 6F

Fig. 7. Differential roles of MKK4/7 in JNK activation. A, B. Serum-starved SVOG-40 (left) and $\alpha$ T3-1 (right) cells were treated with PGF2 $\alpha(10 \mu \mathrm{M})$ and GnRH-a $\left(10^{-7} \mathrm{M}\right)$ for the indicated times or with $\mathrm{VOOH} \mathrm{(V,15} \mathrm{min)}$ as a positive control. Inhibitory (p80MKK4) and activatory ( p 261 M K K 4 ) phosphorylation of MKK4 (A) as well as the activatory phosphorylation of MKK7 (B) were detected by Western blotting using the indicated Abs. C. $\alpha \mathrm{T} 3-1$ cells were transfected with the indicated SiRNAs, serum-starved and stimulated with

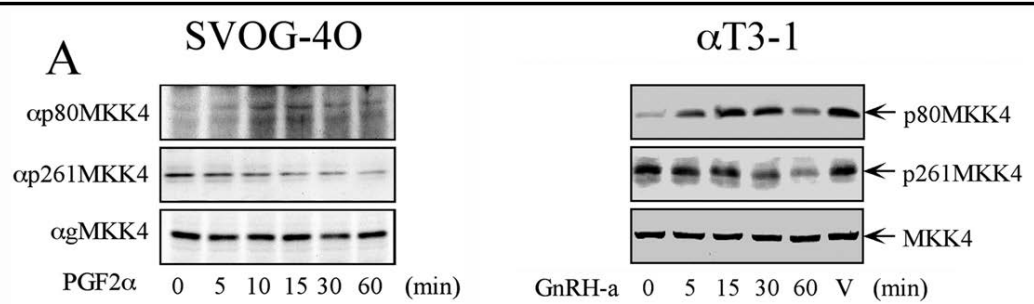

B

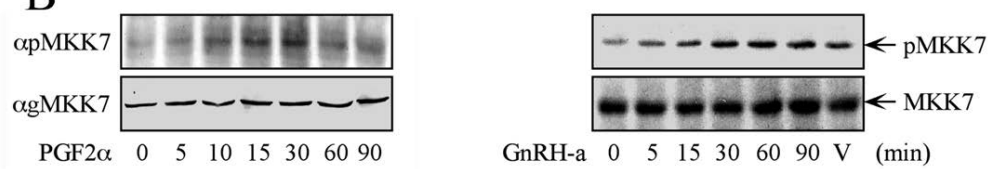

C

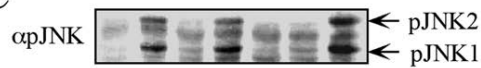
$\alpha \mathrm{gJNK}$ EU

GnRH-a - + - + - +

Si-Cont $++-\cdots$

Si-MKK4 - - + + -

Si-MKK7 - - - - +

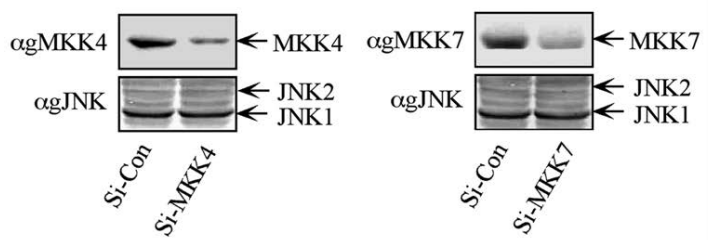

GnRH-a $\left(10^{-7} \mathrm{M} ; 30\right.$

min). Phosphorylation of JNK (upper panels) and the expression levels of MKK4/7 were determined by a Western blotting with the indicated Abs, using the same membrane. First the membrane was blotted with pJNK Ab (upper panel), stripped, blotted with gJNK Ab (second and fourth panels), stripped again and the left side was blotted with MKK4 Ab, while the left part blotted with MKK7 Ab (third panels). 


\section{Cellular Physiology Cell Physiol Biochem 2018;50:121-135

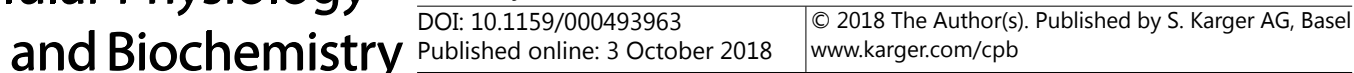 \\ Nadel et al.: Gq-Induced AKT Inactivation in Apoptotic Signaling}

and G) downstream of PKC, but not c-Src (Fig. S4). Therefore, it is likely that the diminished AKT activity upon leads to a reduced inhibition of MLK3, and thereby allows an activatory phosphorylation to prevail and transmit the signal further to the JNK cascade.

\section{Roles of MKK4 and MKK7 in JNK activation}

We then examined the involvement of the MAPKK level kinases of the JNK cascade, namely MKK4 and MKK7 in JNK activation. Since it was previously shown that AKT inhibits MKK4 activity by phosphorylating it on Ser80 [39] we studied whether AKT might be involved in JNK activation via MKK4 as well. However, Western blot with the appropriate Abs showed that the inhibitory MKK4 phosphorylation (pSer80) was in fact increased, whereas the activatory phosphorylation (pSer261) decreased upon stimulations (Fig. 7A), suggesting that MKK4 is not involved in the Gq-AKT-JNK pathway. On the other hand, PGF2 $\alpha$ and GnRH-a stimulation resulted in increased phosphorylation of Ser271/Thr275 of MKK7 (Fig. 7B), indicating that this MAPKK may participate in the examined pathway. To further confirm that JNK activation is mediated by MKK7 and not by MKK4, we knockdown either MKK4 or MKK7 in $\alpha$ T3-1 cells using appropriate SiRNAs. Indeed, when these cells were stimulated with GnRH-a, there was a clear reduction in JNK activation in the MKK7 but not in the MKK4 depleted cells (Fig 7C). Taking together, these results indicate that JNK activation is dependent only on MKK7, whereas MKK4 is in fact inhibited upon the stimulations. These results do not support the notion that both MKK4 and MKK7 are simultaneously required for JNK activation [40], and suggest that each of them is sufficient for this purpose. These differences may be explained either by different cell contexts or varying scaffold proteins that allow full activation by MKK7 alone.

\section{Discussion}

Although Gq proteins mediate mostly proliferation, differentiation and survival, some of them may participate in the induction of apoptosis as well [15]. This was shown in pathological settings such as myocardium hypertrophy [16], or our finding that GnRHR can induce apoptosis in cancer cells [17]. Some sporadic indications for apoptotic effects were suggested for more physiological systems as well [15], but their significance and mechanism of action have not been studied. Here we showed that PKC, which is the main effector of Gq has the ability to reduce the activity of the survival protein AKT, and elevate the activity of the pro-apoptotic kinase JNK. We then analyzed two systems in which GqPCRs were implicated in growth arrest and apoptosis. In both cell lines, stimulation of the examined GqPCR induced apoptosis by activating the same signaling pathway that seems also similar to the one identified in prostate cancer cells [21]. Thus, our results indicate that upon stimulation, Gq transmit its apoptotic signal first by inducing activation of PKC that transmits it further by two separate signaling branches. One is the activation of c-Src that can activate the JNK cascade and the other branch consists of dephosphorylation of AKT. Our results indicate that in resting cells, AKT is highly active due to basal c-Src activity. Upon stimulation, c-Src is activated and induces phosphorylation of MLK3 upstream of the apoptotic JNK cascade. However, the apoptotic signal cannot proceed unless the inhibition at the level of MAP3K of the JNK cascade is alleviated. This is induced by reduction of the activity of AKT by a PKCdependent mechanism, which, together with a phosphatase activity strongly reduces the inhibitory phosphorylation of the MAP3K component MLK3. This further allows signal flow via MKK7 and JNK to induce apoptosis (see a model in Fig. 8).

One of the main regulatory steps of the apoptotic pathway observed here is the decreased AKT activity. Since AKT is a central mediator of cell survival [41], it is not surprising that its inhibition leads to induction of apoptosis. However, unlike other systems in which the activity of AKT in quiescent cells is low and is increased upon stimulation to induce survival, the common phenotype in the cells examined here is the relatively high basal AKT activity. This high activity seems to be induced mainly by a c-Src family member, as the specific c-Src 


\section{Cellular Physiology

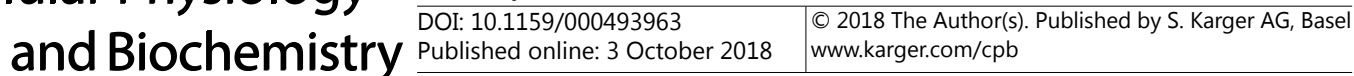 \\ Nadel et al.: Gq-Induced AKT Inactivation in Apoptotic Signaling}

inhibitor PP2 dramatically inhibits it. Our study further demonstrates that c-Src effects on AKT is limited to quiescent cells, but is not involved in the induced inhibition. This is different from the central role of c-SRC in the activation of JNK (Fig. 5) and also ERK [42, 43] downstream of GqPCRs. These differences in c-Src effects before and after stimulation could be a result of an alternative complex formation, as recently reported upon GnRH-a non-apoptotic stimulation of L $\beta$ T2 cells [44]. Alternatively, it can also be due to interference by interacting downstream processes, such as phosphatases or additional inhibitory phosphorylations. Our

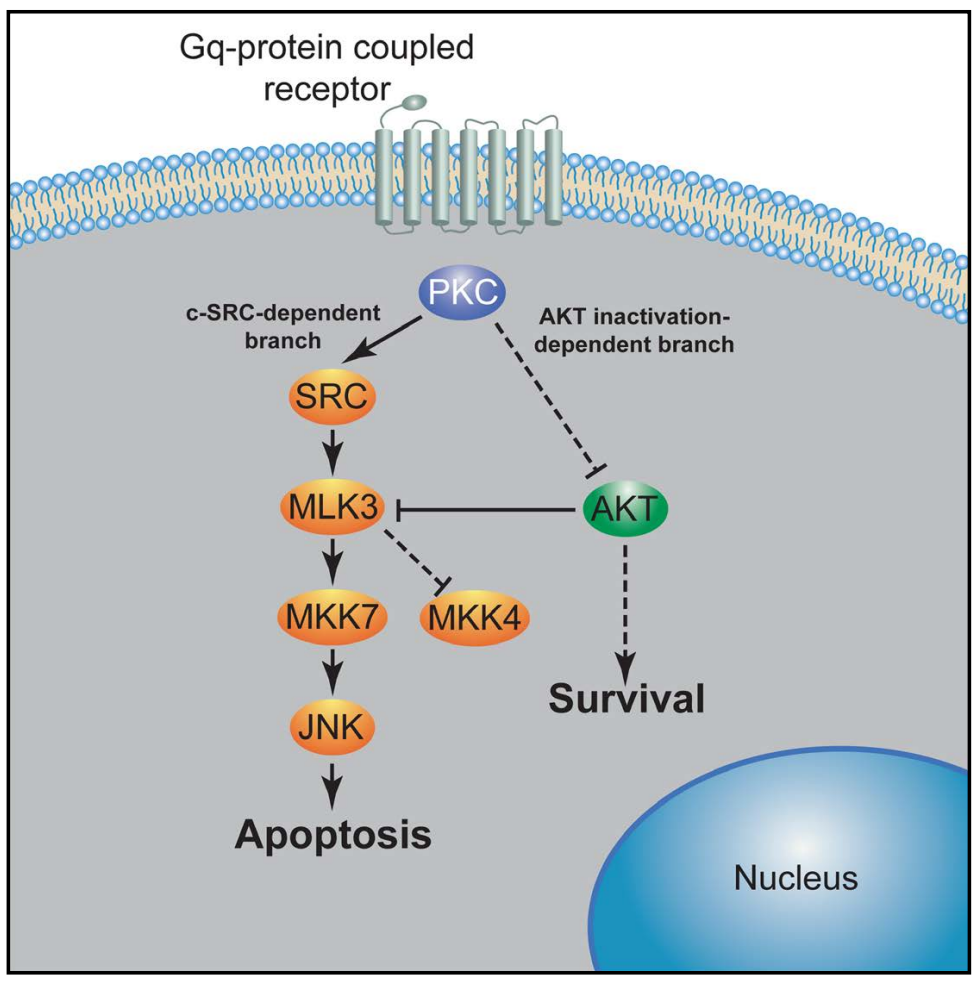

Fig. 8. Schematic representation of the mechanisms that mediate GqPCRinduced apoptosis. The full signaling cascade including Gq, PKC, Src, AKT, MLK3 and the JNK cascade is shown.

findings strengthen our previous unique finding

(16) that GqPCR may inhibit the basal activity of AKT. This effect might be due to the relatively high basal activity of AKT in these non-stimulated cells. Therefore, it is possible that the inhibition of AKT activity by Gq-dependent stimulations in mitogenes (insulin, IGF-1, or EGF)-stimulated cells $[29,30]$ occurs via a similar mechanism to the one identified here.

One of the mechanism by which AKT exerts its anti-apoptotic activity is by inhibiting the apoptotic JNK cascade [45], which was shown here to be a key player in the Gq-induced apoptosis. The mechanism by which AKT inhibits JNK activity has been elucidated in few systems, and found to involve mainly inactivating phosphorylation of MAP3K or MAPKK components of the JNK cascade, including ASK1 [46], MLK3 [38] and MKK4 [39]. We tested all three kinases, and found that only MLK3 is involved in JNK activation in the cells examined here. In addition, we found that the activity of this kinase is suppressed in resting cells by AKT phosphorylation, and this inhibitory phosphorylation is alleviated by reduced AKT activity upon stimulation. Other mechanisms by which AKT regulates the JNK cascade is by regulating JNK scaffold proteins such as JIP1 and POSH $[47,48]$. The involvement of these processes still needs to be clarified in our systems, but it is likely that the upstream effect on MLK3 is sufficient to explain the effects observed here. Independent of the full mechanistic details it is clear from our results that the high basal AKT activity maintains the low activity of JNK in resting cells, and this inhibition is released upon stimulation.

Due to the possible effect of AKT on MKK4 [39], we analyzed the effect of the later in our systems. To our surprise, we found not only that MKK4 was not activated following Gqstimulated AKT inactivation, but rather it was inhibited upon stimulation. Consistently, MKK4 was not involved in JNK activation, which seems to be fully mediated by Gq stimulation of MKK7 in our systems. This is unlike the suggested synergistic and simultaneous activation of JNKs by MKK4 and MKK7 [49], which could be cell-type dependent [50]. Given that MKK4 was active in quiescent cells and since Gq stimulation induced its inactivation, suggests 


\section{Cellular Physiology Cell Physiol Biochem 2018;50:121-135

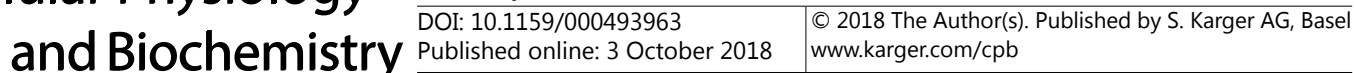 \\ Nadel et al.: Gq-Induced AKT Inactivation in Apoptotic Signaling}

that MKK4 affects a subset of JNK molecules, while the subset responsible for apoptosis is regulated by MKK7. In addition, the elevated Ser80 phosphorylation, which occurred despite the lack of AKT activity, indicates that other kinases that participate in this phosphorylation should be identified.

In the present study, we evaluated the structural luteolysis effect of PGF2 $\alpha$ in the human luteinized granulosa cell line SVOG-40, and found that PGF2 $\alpha$ induced apoptosis of these cells. This result is consistent with previous studies, which also demonstrated that treatment of cultured human luteinized granulosa cells with PGF2 $\alpha$ as well as other cytokines induced apoptotic effect in such cells [33]. Similar effects were detected in granulosa cells of corpus luteum in vivo [51]. Revealing the new signaling pathways may provide new insight into the above physiological processes. Thus, in the human corpus luteum this pathway may help both in the diagnosis and treatment of various reproductive abnormalities, using specific signal transduction modulators. We also found here that $\mathrm{GnRH}-\mathrm{a}$ induces apoptosis in the pituitary gonadotrope $\alpha \mathrm{T} 3-1$ cells. The pathway is likely to be important for pituitary development, and as a consequence to the treatment of prostate cancer by GnRH-a [17]. These results elucidated a physiological mechanism of apoptosis, which involves Gq-mediated and PKCdependent AKT inactivation, leading to reversal of MLK3 inhibition, promoting JNK activation and apoptosis.

\section{Conclusion}

We show here that GqPCRs can act as apoptosis-mediating receptors that act independently from the well-known death receptors in both physiological and pathological systems. The mechanism that allows the GqPCR-induced apoptosis is general, and includes a two-branched pathway downstream of PKC. One branch consists on c-Src activation that transmit the signal to the JNK cascade. However, the signal via this branch can't proceed without the alleviation of an inhibitory phosphorylation on the MLK3, which is mediated by the second branch that consists on PKC-dependent inactivation of AKT and a phosphatase activity. From the MLK3 the signal is transmitted by MKK7, not MKK4, to JNK, which then induces apoptosis.

\section{Acknowledgements}

We would like to thank Mrs. Tamar Hanoch for her technical assistance in this study. This work was supported by a grant from the EU $6^{\text {th }}$ Framework Program (GROWTHSTOP, LSHC CT-2006-037731) and from the Israel Science Foundation. R.S. is an incumbent of the Yale Lewine and Ella Miller Lewine professorial chair for cancer research. Z.N. is the incumbent of the Abraham E. Kazan Chair in Structural Biology.

\section{Disclosure Statement}

The authors declare to have no competing interests.

\section{References}

1 Dorsam RT, Gutkind JS: G-protein-coupled receptors and cancer. Nat Rev Cancer 2007;7:79-94.

2 Bridges TM, Lindsley CW: G-protein-coupled receptors: from classical modes of modulation to allosteric mechanisms. ACS Chem Biol 2008;3:530-541. 


\section{Cellular Physiology Cell Physiol Biochem 2018;50:121-135 \begin{tabular}{l|l|l}
\hline and Biochemistry $10.1159 / 000493963$ & $\begin{array}{l}\text { C) } 2018 \text { The Author(s). Published by S. Karger AG, Basel } \\
\text { www.karger.com/cpb }\end{array}$ \\
\hline
\end{tabular} \\ Nadel et al.: Gq-Induced AKT Inactivation in Apoptotic Signaling}

-3 Syrovatkina V, Alegre KO, Dey R, Huang XY: Regulation, Signaling, and Physiological Functions of G-Proteins. J Mol Biol 2016;428:3850-3868.

4 Hilger D, Masureel M, Kobilka BK: Structure and dynamics of GPCR signaling complexes. Nat Struct Mol Biol 2018;25:4-12.

5 Smrcka AV: G protein betagamma subunits: central mediators of G protein-coupled receptor signaling. Cell Mol Life Sci 2008;65:2191-2214.

-6 Khan SM, Sung JY, Hebert TE: Gbetagamma subunits-Different spaces, different faces. Pharmacol Res 2016;111:434-441.

7 Luttrell LM, Lefkowitz RJ: The role of beta-arrestins in the termination and transduction of G-proteincoupled receptor signals. J Cell Sci 2002;115:455-465.

$>8$ Wu J, Cunnick JM: Trans-regulation of epidermal growth factor receptor by LPA and G protein-coupled receptors. Biochim Biophys Acta 2002;1582:100-106.

-9 Mizuno N, Itoh H: Functions and regulatory mechanisms of Gq-signaling pathways. Neurosignals 2009;17:42-54.

10 Kamato D, Mitra P, Davis F, Osman N, Chaplin R, Cabot PJ, Afroz R, Thomas W, Zheng W, Kaur H, Brimble M, Little PJ: Gaq proteins: molecular pharmacology and therapeutic potential. Cell Mol Life Sci 2017;74:13791390.

11 Offermanns S, Toombs CF, Hu YH, Simon MI: Defective platelet activation in G alpha(q)-deficient mice. Nature 1997;389:183-186.

-12 Offermanns S, Hashimoto K, Watanabe M, Sun W, Kurihara H, Thompson RF, Inoue Y, Kano M, Simon MI: Impaired motor coordination and persistent multiple climbing fiber innervation of cerebellar Purkinje cells in mice lacking Galphaq. Proc Natl Acad Sci U S A 1997;94:14089-14094.

-13 Rozengurt E: Mitogenic signaling pathways induced by G protein-coupled receptors. J Cell Physiol 2007;213:589-602.

14 Kraus S, Naor Z, Seger R: Intracellular signaling pathways mediated by the gonadotropin-releasing hormone (GnRH) receptor. Arch Med Res 2001;32:499-509.

15 New DC, Wu K, Kwok AW, Wong YH: G protein-coupled receptor-induced Akt activity in cellular proliferation and apoptosis. Febs J 2007;274:6025-6036.

16 Adams JW, Brown JH: G-proteins in growth and apoptosis: lessons from the heart. Oncogene 2001;20:16261634.

17 Kraus S, Naor Z, Seger R: Gonadotropin-releasing hormone in apoptosis of prostate cancer cells. Cancer Lett 2006;234:109-123.

18 Cigola E, Kajstura J, Li B, Meggs LG, Anversa P: Angiotensin II activates programmed myocyte cell death in vitro. Exp Cell Res 1997;231:363-371.

19 Adams JW, Sakata Y, Davis MG, Sah VP, Wang Y, Liggett SB, Chien KR, Brown JH, Dorn GW 2nd: Enhanced Galphaq signaling: a common pathway mediates cardiac hypertrophy and apoptotic heart failure. Proc Natl Acad Sci U S A 1998;95:10140-10145.

-20 Flanagan CA, Manilall A: Gonadotropin-Releasing Hormone (GnRH) Receptor Structure and GnRH Binding. Front Endocrinol (Lausanne) 2017;8:274.

21 Kraus S, Levy G, Hanoch T, Naor Z, Seger R: Gonadotropin-releasing hormone induces apoptosis of prostate cancer cells: role of c-Jun NH2-terminal kinase, protein kinase B, and extracellular signal-regulated kinase pathways. Cancer Res 2004;64:5736-5744.

22 Althoefer H, Eversole-Cire P, Simon MI: Constitutively active Galphaq and Galpha13 trigger apoptosis through different pathways. J Biol Chem 1997;272:24380-24386.

23 Ueda H, Morishita R, Itoh H, Narumiya S, Mikoshiba K, Kato K, Asano T: Galpha11 induces caspasemediated proteolytic activation of Rho-associated kinase, ROCK-I, in HeLa cells. J Biol Chem 2001;276:42527-42533.

24 Miyamoto S, Howes AL, Adams JW, Dorn GW, 2nd, Brown JH: Ca2+ dysregulation induces mitochondrial depolarization and apoptosis: role of $\mathrm{Na}+\mathrm{Ca} 2+$ exchanger and AKT. J Biol Chem 2005;280:38505-38512.

25 Lorenz K, Schmitt JP, Schmitteckert EM, Lohse MJ: A new type of ERK1/2 autophosphorylation causes cardiac hypertrophy. Nat Med 2009;15:75-83.

-26 Vanhaesebroeck B, Stephens L, Hawkins P: PI3K signalling: the path to discovery and understanding. Nat Rev Mol Cell Biol 2012;13:195-203. 


\section{Cellular Physiology Cell Physiol Biochem 2018;50:121-135 \begin{tabular}{l|l} 
and Biochemistry & DOI: 10.1159/000493963 \\
Published 2018 The Author(s). Published by S. Karger AG, Basel \\
www.karger.com/cpb
\end{tabular}

27 Franke TF: PI3K/Akt: getting it right matters. Oncogene 2008;27:6473-6488.

28 Duronio V: The life of a cell: apoptosis regulation by the PI3K/PKB pathway. Biochem J 2008;415:333-344.

29 Rose A, Froment P, Perrot V, Quon MJ, LeRoith D, Dupont J: The luteinizing hormone-releasing hormone inhibits the anti-apoptotic activity of insulin-like growth factor-1 in pituitary alphaT3 cells by protein kinase Calpha-mediated negative regulation of Akt. J Biol Chem 2004;279:52500-52516.

-30 Ueda H, Morishita R, Narumiya S, Kato K, Asano T: Galphaq/11 signaling induces apoptosis through two pathways involving reduction of Akt phosphorylation and activation of RhoA in HeLa cells. Exp Cell Res 2004;298:207-217.

-31 Wu EH, Tam BH, Wong YH: Constitutively active alpha subunits of G(q/11) and G(12/13) families inhibit activation of the pro-survival Akt signaling. FEBS J 2006;273:2388-2398.

32 Boussif O, Lezoualc'h F, Zanta MA, Mergny MD, Scherman D, Demeneix B, Behr JP: A versatile vector for gene and oligonucleotide transfer into cells in culture and in vivo: polyethylenimine. Proc Natl Acad Sci U S A 1995;92:7297-7301.

-33 Matsubara H, Ikuta K, Ozaki Y, Suzuki Y, Suzuki N, Sato T, Suzumori K: Gonadotropins and cytokines affect luteal function through control of apoptosis in human luteinized granulosa cells. J Clin Endocrinol Metab 2000;85:1620-1626.

-34 Stocco C, Telleria C, Gibori G: The molecular control of corpus luteum formation, function, and regression. Endocr Rev 2007;28:117-149.

35 Kim HG, Bhagavath B, Layman LC: Clinical manifestations of impaired GnRH neuron development and function. Neurosignals 2008;16:165-182.

-36 Naor Z, Benard O, Seger R: Activation of MAPK Cascades by GPCRs: The Case of Gonadotropin-releasing Hormone Receptor. Trends Endocrinol Metab 2000;11:91-99.

-37 Levi NL, Hanoch T, Benard O, Rozenblat M, Harris D, Reiss N, Naor Z, Seger R: Stimulation of Jun N-terminal kinase (JNK) by gonadotropin-releasing hormone in pituitary alpha T3-1 cell line is mediated by protein kinase C, c-Src, and CDC42. Mol Endocrinol 1998;12:815-824.

38 Barthwal MK, Sathyanarayana P, Kundu CN, Rana B, Pradeep A, Sharma C, Woodgett JR, Rana A: Negative regulation of mixed lineage kinase 3 by protein kinase B/AKT leads to cell survival. J Biol Chem 2003;278:3897-3902.

39 Park HS, Kim MS, Huh SH, Park J, Chung J, Kang SS, Choi EJ: Akt (PKB) negatively regulates SEK1 by means of protein phosphorylation. J Biol Chem 2002;277:2573-2578.

40 Wang X, Destrument A, Tournier C: Physiological roles of MKK4 and MKK7: insights from animal models. Biochim Biophys Acta 2007;1773:1349-1357.

41 Manning BD, Cantley LC: AKT/PKB signaling: navigating downstream. Cell 2007;129:1261-1274.

-42 Benard O, Naor Z, Seger R: Role of dynamin, Src, and Ras in the protein kinase C-mediated activation of ERK by gonadotropin-releasing hormone. J Biol Chem 2001;276:4554-4563.

43 Kraus S, Benard O, Naor Z, Seger R: c-Src is activated by EGF-receptor in a pathway that mediates JNK and ERK activation by gonadotropin-releasing hormone in COS7 cells. J Biol Chem 2003;278:15.

-44 Dobkin-Bekman M, Naidich M, Rahamim L, Przedecki F, Almog T, Lim S, Melamed P, Liu P, Wohland T, Yao Z, Seger R, Naor Z: A preformed signaling complex mediates GnRH-activated ERK phosphorylation of paxillin and FAK at focal adhesions in L beta T2 gonadotrope cells. Mol Endocrinol 2009;23:1850-1864.

-45 Dhanasekaran DN, Reddy EP: JNK signaling in apoptosis. Oncogene 2008;27:6245-6251.

-46 Kim AH, Khursigara G, Sun X, Franke TF, Chao MV: Akt phosphorylates and negatively regulates apoptosis signal-regulating kinase 1. Mol Cell Biol 2001;21:893-901.

-47 Kim AH, Yano H, Cho H, Meyer D, Monks B, Margolis B, Birnbaum MJ, Chao MV: Akt1 regulates a JNK scaffold during excitotoxic apoptosis. Neuron 2002;35:697-709.

48 Figueroa C, Tarras S, Taylor J, Vojtek AB: Akt2 negatively regulates assembly of the POSH-MLK-JNK signaling complex. J Biol Chem 2003;278:47922-47927.

49 Raman M, Chen W, Cobb MH: Differential regulation and properties of MAPKs. Oncogene 2007;26:31003112.

50 Tournier C, Dong C, Turner TK, Jones SN, Flavell RA, Davis RJ: MKK7 is an essential component of the JNK signal transduction pathway activated by proinflammatory cytokines. Genes Dev 2001;15:1419-1426.

51 Rueda BR, Wegner JA, Marion SL, Wahlen DD, Hoyer PB: Internucleosomal DNA fragmentation in ovine luteal tissue associated with luteolysis: in vivo and in vitro analyses. Biol Reprod 1995;52:305-312. 